\title{
Histopathological Profile of Skin Adnexal Tumours - A Three Year Experience at a Tertiary Care Centre in Manipur
}

\author{
Deepa Longjam¹ ${ }^{1}$ L. Sushila Devi², Radita L. ${ }^{3}$, KH Sunitarani Devi ${ }^{4}$
}

\begin{abstract}
${ }^{1}$ Department of Pathology, J. N. Institute of Medical Sciences, Imphal, Manipur, India. ${ }^{2}$ Department of Pathology, J. N. Institute of Medical Sciences, Imphal, Manipur, India. ${ }^{3}$ Department of Pathology, J. N. Institute of Medical Sciences, Imphal, Manipur, India. ${ }^{4}$ Department of Pathology, J. N. Institute of Medical Sciences, Imphal, Manipur, India.
\end{abstract}

\section{ABSTRACT}

\section{BACKGROUND}

Skin adnexal tumours are a large group of benign and malignant tumours that arise from pluripotent stem cells and differentiate toward one or more adnexal structures. So, quite often they may exhibit more than one line of differentiation (hybrid tumours). Moreover, they are uncommon, clinically nonspecific, and remain a diagnostic challenge to surgeons and pathologists alike. The present study is aimed at analysing the histopathological profile of skin adnexal tumours in a hospital based population in Manipur.

\section{METHODS}

The present study is a retrospective analysis conducted over a period of 3 years from January 2017 to December 2019 in the Department of Pathology, Jawaharlal Institute of Medical Sciences, Manipur, India. Specimens were fixed in formalin, paraffin embedded and stained with haematoxylin and eosin for histopathologic analysis.

\section{RESULTS}

A total of 34 cases of skin adnexal tumours were reported in the Department of Pathology, JNIMS, Imphal, over a period of 3 years out of which $94 \%(32 / 34)$ of the total cases were benign tumours and 5.88\% (2/34) were malignant tumours. Tumours with hair follicle differentiation comprised the largest group (44.1\%). Pilomatrixoma was the most common tumour followed by Nevus Sebaceous. Both malignant adnexal tumours were sebaceous carcinomas.

\section{CONCLUSIONS}

Skin adnexal tumours are uncommon tumours with most of them being benign tumours and there is a low incidence of malignant tumours. Malignant tumours although rare, need to be diagnosed accurately since they can be aggressive with distant and nodal metastasis. Histopathologic examination remains the gold standard in diagnosing these rare lesions.

\section{KEY WORDS}

Skin Adnexal Tumours, Histopathology, Pilomatrixoma, Nevus Sebaceous
Corresponding Author:

Dr. Deepa Longjam,

Department of Pathology,

J. N. Institute of Medical Sciences,

Imphal, Manipur, India.

E-mail:

umeshtakhelmayum2014@gmail.com

DOI: $10.14260 / \mathrm{jemds} / 2020 / 394$

Financial or Other Competing Interests: None.

How to Cite This Article:

Longjam D, Devi LS, Radita L, et al. Histopathological profile of skin adnexal tumours- a three year experience at a tertiary care centre in Manipur. J. Evolution Med. Dent. Sci. 2020;9(24): 1804-1808, DOI:

10.14260/jemds/2020/394

Submission 08-03-2020,

Peer Review 19-05-2020,

Acceptance 27-05-2020,

Published 15-06-2020.

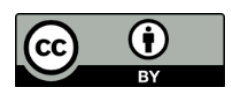




\section{BACKGROUND}

Skin adnexal tumours have been aptly described as troublesome tumours by D Cotton. ${ }^{1}$ They include a wide spectrum of epithelial tumours and encompasses hamartomas, hyperplasias, benign and malignant tumours. ${ }^{2,3}$ They are derived from multipotent stem cells and can differentiate toward one or more adnexal structures namely pilosebaceous unit, eccrine glands and apocrine glands. ${ }^{3,4}$ Therefore a single tumour may exhibit a wide spectrum of differentiation which makes precise categorization difficult. 5 Tumours of hair follicular origin usually differentiate towards many of the normal follicular components and are named accordingly.

They are broadly divided into hamartomas of hair germ, tumours of hair germ, tumour of hair matrix, tumours of external hair sheath, tumours of perifollicular mesenchyme, tumours of intraepidermal follicles and infundibulum. Similarly the eccrine sweat glands also consists of many functionally and morphologically different regions. The intraepidermal duct gives rise to hidroacanthoma simplex, poroma and dermal duct tumours. Syringoma and spiradenoma derived from intradermal straight duct. Cylindroma arises from the intradermal coil duct. The secretory coil give rise to hydradenoma. ${ }^{1}$ In general the hyperplasia, cysts and hamartomas are made up of mature or nearly mature appendageal elements, the benign tumours exhibit less complete differentiation even so well developed differentiated or partially differentiated elements are still present. The malignant adnexal tumours have a low degree of differentiation and may be devoid of differentiated structures. ${ }^{2}$

The clinical presentation of these tumours are very nonspecific and histopathologic examination remains the mainstay of diagnosis. ${ }^{3}$ Immunohistochemistry is thought to be of little value in definitely differentiating the various adnexal tumours. ${ }^{2}$ Majority of these adnexal tumours are benign and is treated by complete local excision and carries no risk of a relapse. Therefore exact subtyping of these benign tumours is thought to be an academic exercise without affecting treatment.1,3 However occurrence of some of these appendageal tumours may indicate presence of internal visceral malignancies for example multiple trichilemmomas in Cowden syndrome and sebaceous tumours in Muir Torre syndrome.3,4 Malignant adnexal tumours are comparatively rare.1,3,4

They can usually be differentiated from the benign counterparts by their contrasting silhouette/ architectural patterns on scanner magnification as first described by Bernard Ackerman.1,3,5 It has been tradition to rely on cytologic and nuclear atypia to differentiate benign and malignant tumours. However when it comes to adnexal tumours these conventional criteria are not helpful in distinguishing benign from malignant tumours. The architectural criteria described by Ackerman were symmetry vs asymmetry, well-circumscribed vs ill-circumscribed margins, smooth vs jagged borders, vertical orientation vs horizontal orientation, whether lesion is V shaped, presence of compressed fibrous tissues around the tumours, clefting between tumour cells and stroma, clefting between surrounding stroma and compressed fibrous tissue, incomplete vs complete shelling out of the lesion, presence of ulceration, necrosis, uniform vs irregular cell nests, discrete nests, shape of cell nests, epithelial cells in single and preservation of adnexa within the lesion. ${ }^{5} \mathrm{D}$ Cotton is of the opinion that there are two settings of adnexal carcinoma: those which are thought to arise from benign adnexal tumours and those which appear to be malignant from inception. Though uncommon the malignant tumours can be clinically aggressive with potential for nodal and distant metastasis. Hence it is important to recognise these tumours correctly for therapeutic and prognostic purposes. ${ }^{3,4}$

As there are very few studies on adnexal tumours from the north-eastern part of India, the present study was conducted to determine the characters of skin adnexal tumours with regards to their frequency, histological subtype, benign or malignant nature and age distribution.

\section{METHODS}

The present study is a retrospective analysis conducted over a period of 3 years from January 2017 to December 2019 in the Department of Pathology, Jawaharlal Nehru Institute of Medical Sciences, Manipur, India. The study was approved by Institutional Ethics Committee. All identifiers were removed, and strict confidentiality was maintained for all collected data. Histopathological examination was done on formalin fixed, paraffin embedded sections which were stained with hematoxylin and eosin. Clinical data's were recorded from the histopathology requisition forms. The adnexal tumours were diagnosed according to the literature from Lever's Histopathology of Skin $11^{\text {th }}$ ed and categorised as per the latest WHO classification. ${ }^{2}$ Differentiation between benign and malignant tumours was aided by the criteria listed by Rajlaksmi Tirumale et al. ${ }^{5}$ Histomorphological analysis of the tumours were done under the microscope and classified based on predominant differentiation into follicular, sebaceous, eccrine and apocrine.

\section{Inclusion Criteria}

A total of 34 cases diagnosed as skin adnexal tumours on histopathology were included in the study. Sample size is taken based on the convenience of the study

\section{Exclusion Criteria}

All non-neoplastic lesions.

\section{Statistical Analysis}

Data collected were entered in MS Excel spreadsheet 2017 and checked for consistency. Descriptive statistics like mean and proportions were calculated. 


\section{RESULTS}

In this study, out of the total 5953 cases reported in histopathology section of our department from January 2017 to December 2019 only 34 cases $(0.57 \%)$ were reported as skin adnexal tumours. Study comprised 14 males and 20 females with a ratio of $0.7: 1$ (Table 1). The age of the patients ranged from 6 years to 72 years (Table 2). The most common age group affected was 21-30 years (23\%) followed by 11-20 years (17.6\%). Malignant tumours affected elderly age group (>61 years).

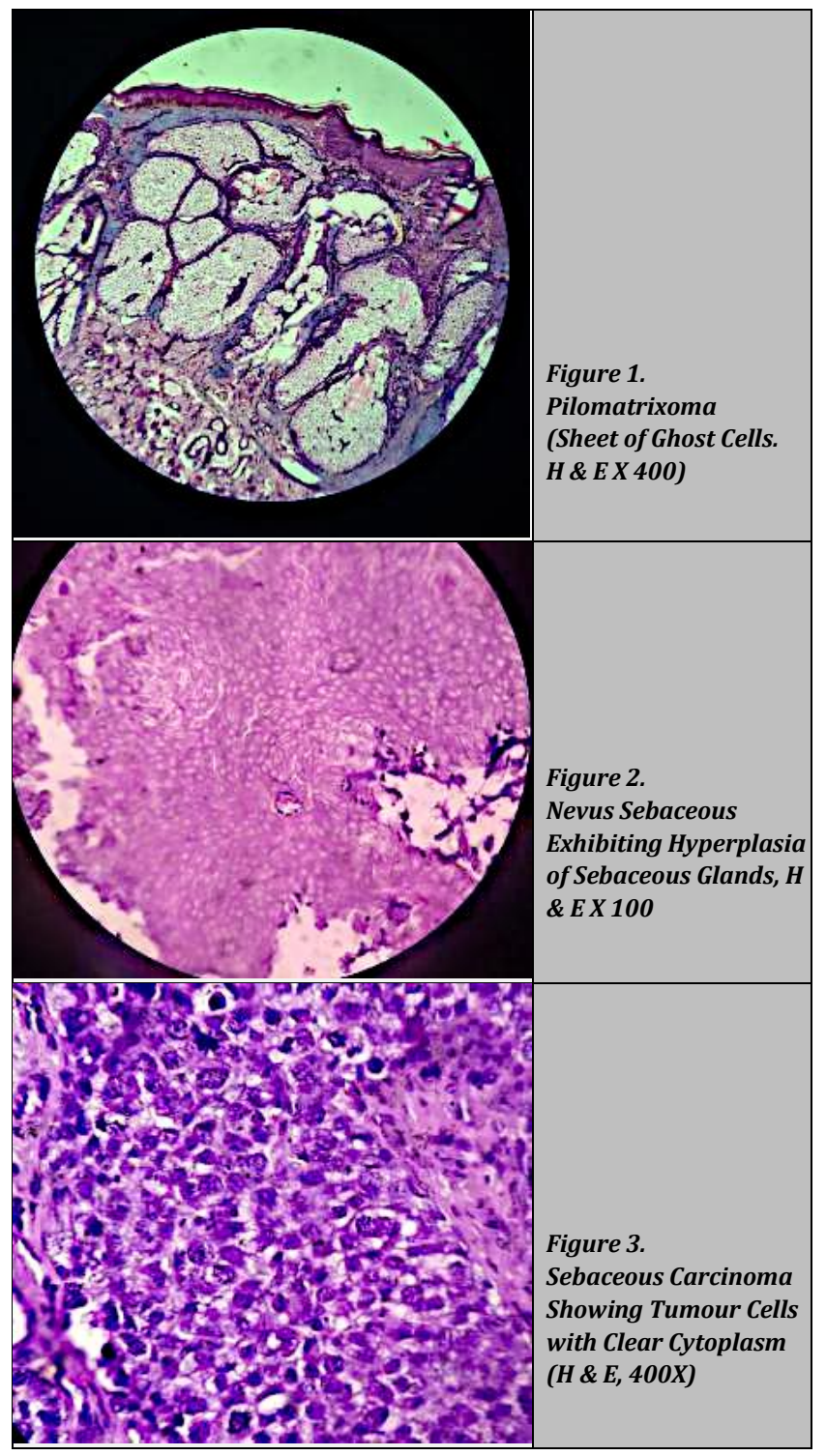

\begin{tabular}{|c|c|c|c|}
\hline Sl. No. & Sex & No. of Cases & Percentage \\
\hline 1. & Male & 14 & $41.17 \%$ \\
\hline 2. & Female & 20 & $58.82 \%$ \\
\hline \multicolumn{4}{|c|}{ Table 1. Sex Distribution of Skin Adnexal Tumours } \\
\hline
\end{tabular}

\begin{tabular}{|ccc|}
\hline Sl. No. & Age Group in Years & Number of Cases with Percentage \\
1. & $0-10$ years & $1(2.94 \%)$ \\
2. & $11-20$ years & $6(17.64 \%)$ \\
3. & $21-30$ years & $8(23.5 \%)$ \\
4. & $31-40$ years & $5(14.7 \%)$ \\
5. & $41-50$ years & $5(14.7 \%)$ \\
6. & $51-60$ years & $3(8.82 \%)$ \\
7. & $61-70$ years & $4(12.7 \%)$ \\
8. & $71-80$ years & $2(5.88 \%)$ \\
9. & $81-90$ years & $0(\mathrm{Nil})$ \\
\hline \multicolumn{3}{c}{ Table 2. Age Distribution of Skin Adnexal Tumours } \\
\hline
\end{tabular}

In the present study out of 34 adnexal tumours, 32 (94\%) were diagnosed as benign comprising the major group and there were only 2 cases $(5.88 \%)$ of malignant adnexal tumours. In our analysis, tumours with hair follicle differentiation constituted the largest group comprising 15 cases (44.1\%) followed by tumours with sebaceous differentiation with 12 cases (35.29\%). The distribution of tumours with apocrine and eccrine differentiation were same being 3 cases each (Table 3).

\begin{tabular}{|c|c|c|}
\hline $\begin{array}{l}\text { Sl. } \\
\text { No. }\end{array}$ & $\begin{array}{l}\text { Behaviour of the } \\
\text { Tumour }\end{array}$ & $\begin{array}{l}\text { Total Number of Cases } \\
\text { with Percentage }\end{array}$ \\
\hline A. & Benign & $32(94.11 \%)$ \\
\hline \multirow[t]{2}{*}{1} & $\begin{array}{c}\text { Tumours with Hair Follicle } \\
\text { Differentiation }\end{array}$ & $15(44.1 \%)$ \\
\hline & $\begin{array}{c}\text { Pilomatrixoma } \\
\text { Trichoepithelioma }\end{array}$ & $\begin{array}{l}10(29.4 \%) \\
05(14.7 \%)\end{array}$ \\
\hline \multirow[t]{2}{*}{2} & $\begin{array}{l}\text { Tumours with Sebaceous } \\
\text { Differentiation }\end{array}$ & $11(32.3 \%)$ \\
\hline & $\begin{array}{c}\text { Nevus sebaceous } \\
\text { Sebaceous hyperplasia }\end{array}$ & $\begin{array}{l}09(26.4 \%) \\
02(5.88 \%)\end{array}$ \\
\hline \multirow[t]{3}{*}{3} & Tumours with Apocrine Differentiation & $03(8.82 \%)$ \\
\hline & $\begin{array}{l}\text { Hidradenoma papilliferum } \\
\text { Syringocystadenoma papilliferum }\end{array}$ & $\begin{array}{l}01(2.94 \%) \\
01(2.94 \%)\end{array}$ \\
\hline & Apocrine hidrocystoma & $01(2.94 \%)$ \\
\hline \multirow[t]{2}{*}{4} & Tumours with Eccrine Differentiation & $03(8.82 \%)$ \\
\hline & $\begin{array}{l}\text { Nodular hydradenoma } \\
\text { Syringoma }\end{array}$ & $01(2.94 \%)$ \\
\hline B. & $\begin{array}{l}\text { Eccrine spiradenoma } \\
\text { Malignant }\end{array}$ & $\begin{array}{l}01(2.94 \%) \\
02(5.88 \%)\end{array}$ \\
\hline 1. & Sebaceous carcinoma & $02(5.88 \%)$ \\
\hline \multicolumn{3}{|c|}{ Table 3. Distribution of Skin Adnexal Tumours in Our Study } \\
\hline
\end{tabular}

Pilomatrixoma (Figure 1) was the most common benign tumour in our study with 10 cases $(29.41 \%)$ followed by nevus sebaceous (Figure 2) with 9 cases $(26.40 \%)$. The two cases of malignant adnexal tumours were both sebaceous carcinomas (Figure 3).

\section{DISCUSSION}

Skin adnexal tumours are a heterogenous group of tumours with differentiation towards any of the epidermal appendages namely hair follicles, sebaceous gland, apocrine and eccrine glands. They are uncommon, often misdiagnosed clinically and exhibit a bewildering array of differentiation. A single tumour may also show evidence of more than one lineage. Histopathology remains the mainstay in diagnosing these tumours. In the present study the incidence of skin adnexal tumours was very low $(0.57 \%)$ as observed in studies conducted by several authors.5,6,7,8 Rajlakshmi et al found an incidence of only $0.0128 \%$ of all cases. ${ }^{6}$

In our study we observed only tumours with a single line of differentiation as also observed by Rajlakshmietal.65kin adnexal tumours in our study showed a wide range of age distribution ranging from 6 years to 72 years. The maximum number of cases was reported in the age group of 21-30 years in this study whereas Jyotsna et $\mathrm{al}^{4}$ reported the commonest age group as 31-40 years, Vani $\mathrm{D}$ et $\mathrm{al}^{7}$ as $40-49$ years and Pujani $\mathrm{M}$ et $\mathrm{al}^{8}$ as $21-40$ years. In our study there was a slight female preponderance with a female to male ratio of 1:0.7 which is similar to the studies of Kanwalpreet $\mathrm{K}$ et al, ${ }^{3}$ Vani $\mathrm{D}$ et al, ${ }^{7}$ Ankit Sharma et al ${ }^{9}$ and RadhikaK et al ${ }^{10}$. The majority of the adnexal tumours were benign in nature in this study (94\%) with only 2 cases of malignant adnexal tumours. All studies reported prevalence of benign tumours. Kanwalpreet $\mathrm{K}$ et $\mathrm{al}^{3}$ reported an incidence of $80.36 \%$, Jyotsna Suriet $\mathrm{al}^{4}$ 
93.94\%, V Rajlakshmi et al ${ }^{6} 90.48 \%$, Vani et al ${ }^{7}$, PujaniM et $\mathrm{al}^{8}$ $96 \%$, Ankit Sharma et al $^{9} 80.36 \%$ and Radhika K et al ${ }^{10}$ $77.1 \%$. The benign tumours in our analysis were well circumscribed with smooth borders, showed presence of residual adnexal structures with absence of ulceration and necrosis. The malignant tumours were polycircumscribed and showed an infiltrative growth pattern with prominent comedone necrosis.

Tumours with follicular differentiation was the most common subtype in our study which was also observed by Kanwalpreet $\mathrm{K}$ et $\mathrm{al}^{3}$, Jyotsna Suriet $\mathrm{al}^{4}$,El Ochi MR et al ${ }^{11}$ and Paudyal et al ${ }^{12}$ whereas sweat gland tumours accounted for the largest numbers of cases in studies conducted by Pujani M et al, ${ }^{8}$ Ankit Sharma et $\mathrm{al}^{9}$ and Radhika $\mathrm{K}$ et al. ${ }^{10}$ Pilomatrixoma was observed as the most common benign tumour in our case which is similar to studies of Kanwalpreet K et $\mathrm{al}^{3}$ Jyotsna Suri et $\mathrm{al}^{4}{ }^{4}$ Ankit Sharma et al, ${ }^{9}$ El Ochi et al ${ }^{11}$, Paudyal et $\mathrm{al}^{12}$ and K. Y. Song et $\mathrm{al}^{13}$. Pilomatrixoma on microscopy is a dermal tumour composed of islands of basiloid cells with ghost cells in the centre. Foreign body giant cells and calcification are frequently found. Naevus sebaceous was the second most common adnexal tumour observed in our study which is similar to the findings of Jyotsna Suri et al. Clinically the natural history of naevus sebaceous evolves through three stages - the infantile stage, the puberty stage and the neoplastic stage. The histology of naevus sebaceous depends on the stage of the lesion. Commonly observed features on microscopy are epidermal changes in the form of acanthosis, papillomatosis and hyperkeratosis along with presence of hyperplastic sebaceous glands and immature hair follicles. The neoplastic stage usually occurs in late adulthood and has the potential to be associated with a range of secondary benign and malignant tumours. These include benign tumours such as tricho blastoma, syringocystadenoma, papilliferum, trichilemmoma, sebaceoma, nodular hydradenoma, hidrocystoma and eccrine poroma. Secondary malignant degeneration is less common and majority of them are basal cell carcinoma and less commonly squamous cell carcinoma, sebaceous and apocrine carcinoma. ${ }^{14,15}$ Among the apocrine tumours, we encountered a single care case of apocrine hidrocystoma. They present as a dermal cystic lesion often with multilocation and lined by columnar cells with eosinophilic cytoplasm. Sebaceous carcinoma was the only subtype of malignant adnexal tumours observed in our present study and it constituted $5.88 \%$ of the total cases $(2 / 34$ cases) which was also observed by Kanwalpreet $\mathrm{K}$ et al, ${ }^{3}$ Jyotsana Suri et $\mathrm{al}^{4}$ and Ankit Sharma et al. ${ }^{9}$

Immunohistochemistry is of little help in differentiating the various adnexal tumours. If desired some of the markers that can be used are epithelial membrane antigen, HMFG (for sebaceous differentiation), cytokeratin (for follicular differentiation), carcinoembryonic antigen (CEA for ductal differentiation).1,2,8 Cytochemical stains may be used as an aid in establishing a diagnosis such as periodic acid Schiff (PAS) which stains the eosinophilic globules of spiradenoma, alcian blue which highlight the stroma in chondroid syringoma. ${ }^{8}$

\section{CONCLUSIONS}

Skin adnexal tumours pose diagnostic challenges to dermatologists, surgeons, and pathologists alike. The diagnosis of an adnexal tumour is usually unsuspected clinically in most of the cases. Hence, there is often a discrepancy between clinical and histopathological diagnosis. Therefore, pathologists should be well versed with the histopathology of this wide range of adnexal tumours. These tumours many a times exhibit more than one line of differentiation making exact categorisation difficult. Most of these adnexal tumours are benign with a low incidence of malignant tumours. Though rare, malignant adnexal tumours have an aggressive clinical course with potential for nodal and distant metastasis. Therefore, it is important to correctly recognise the malignant skin adnexal tumours for therapeutic and prognostic purposes.

\section{REFERENCES}

[1] Cotton D. Troublesome tumours. 1: adnexal tumours of the skin. J Clin Pathol 1991:44(7):543-8.

[2] Ahmed TS, Priore JD, SeykoraJ T. Tumours of epidermal appendages. In: Elder DE, ed. Lever's histopathology of skin. $11^{\text {th }}$ edn. Philadelphia: Lippincott Williams and Wilkins 2015:851-909.

[3] Kaur K, Gupta K, Hemrajani D, et al. Histopathological analysis of skin adnexal tumours: a three year study of 110 cases at a tertiary care centre. Indian J Dermatol 2017;62(4):400-6.

[4] Suri J, Gupta D, Koul KK, et al. A clinicopathological analysis of skin adnexal tumours: four year retrospective study. JK Science 2016;18(4):248-51.

[5] Tirumalae R, Roopa MO. Benign vs malignant skin adnexal neoplasms: how useful are silhouettes? Indian J of Dermatol 2013;58(1):30-3.

[6] Rajalakhmi V, Selvakumar S, Rajeswari K, et al. Case series of skin adnexal tumours. J Clin Diagn Res 2014;8(9):FC07-10.

[7] Vani D, Ashwini NS, Drsandhya M, et al. A 5 year histopathological study of skin adnexal tumours at a tertiary care hospital. IOSR Journal of Dental and Medical Sciences (IOSR-JDMS) 2015:14(4):1-5.

[8] Pujani M, Madaan GB, Jairajpuri ZS, et al. Adnexal tumours of skin: an experience at a tertiary care centre at Delhi. Ann Med Health Sci Res 2016;6(5):280-5.

[9] Sharma A, Paricharak DG, Nigam JS, et al. Histopathological study of skin adnexal tumoursinstitutional study in south India. J Skin Cancer 2014;2014:1-4.

[10] Radhika K, Phaneendra BV, Rukmangadha N, et al. A study of biopsy confirmed skin adnexal tumours: experience at a tertiary care teaching hospital. J Clin Sci Res 2013;2(3):132-8.

[11] El Ochi MR, Boudhas A, Allaoui M, et al. Skin adnexal tumors: histological study about 96 cases. Pan Afr med J 2015;20:389. 
[12] Paudyal P, Agarwal M, Pradhan A, et al. A clinicohistopathological study on skin appendageal tumors. J Pathol Nepal 2016;6:885-91.

[13] Song KY, Yoon DH, Ham EK, et al. Clinico-pathological study on skin appendage tumours. Korean J Pathol 1989;23:111-21.
[14] Kelati A, Baybay H, Gallouj S, et al. Dermoscopic analysis of nevus sebaceus of Jadassohn: a study of 13 cases. Skin Appendage Disord 2017;3(2):83-91.

[15] Simi CM, Rajalakshmi T, Correa M. Clinicopathologic analysis of 21 cases of nevus sebaceus: a retrospective study. Indian J Dermatol Venereol Leprol 2008;74(6):625-7. 